\title{
Ketelitian Pemasangan Tangga Bus Menggunakan Sensor Ultrasonik
}

\author{
Yurianto*, Yusuf Umardani, Zakaria Frani Prasetia \\ Departemen Teknik Mesin, Fakultas Teknik, Universitas Diponegoro \\ Jl. Proft. Sudharto., Tembalang-Semarang 50275, Telp. +62247460059 \\ *E-mail: yurianto_narimin@yahoo.com
}

\begin{abstract}
The bus is popular public transport in Indonesia. Step by step starts with the product design process, stripe off, frame, body assembling, metal finish, putty, painting, trimming \& Finishing to Pre Delivery Inspection. In the assembly of the bus needs to be careful even though this problem is often not attention. The purpose and benefits of this study are to design and implement a tool for installing bus ladders with ultrasonic sensors. The benefit of the study to increase the accuracy of installation of the bus ladders. The installation of steep stairs, the material used in the manufacture of step stairs is iron and plate where the main requirements are not looked twisted. One of the tools needed is an ultrasonic sensor made for the accuracy of the step ladder. This test starts by taking data, entering data into the program, writing programs test, uploading programs to prototypes, and prototypes test. From the sensor test obtained the accuracy value with $1 \mathrm{~mm}$ tolerance of actual size. These tolerances categorized as the safe installation of the bus stairs. These tolerances categorized as a safe bus ladder installation. The stairs mounted to produce the desired accuracy. The installed ladder produces the as the desired accuracy. Reduce quality control work with expected accuracy. Can avoid failure occurred when the stairs installed.
\end{abstract}

Keywords: inspection, accuracy, step, ultrasonic, sensor

\begin{abstract}
Abstrak
Bus adalah transportasi umum yang populer di Indonesia. Tahap demi tahap mulai dari proses product design, stripe off, rangka, body assembling, metal finish, dempul, painting, trimming \& finishing, hingga pre delivery inspection. Dalam perakitan bus harus berhati-hati meskipun masalah ini sering tidak diperhatikan. Tujuan dan manfaat dari kajian ini adalah merancang dan menerapkan alat bantu pemasangan tangga bus dengan sensor ultrasonic. Manfaat penelitian untuk meningkatkan akurasi pemasangan tangga bus. Pemasangan tangga yang curam, material yang digunakan dalam pembuatan tangga tanjakan adalah besi dan plat dimana persyaratan utama tidak tampak bengkok. Salah satu alat yang dibutuhkan adalah sensor ultrasonik yang dibuat untuk keakuratan tangga langkah. Tes ini dimulai dengan mengambil data, memasukkan data ke dalam program, menulis tes program, mengunggah program ke prototipe, dan menguji prototipe. Dari uji sensor diperoleh nilai akurasi dengan toleransi $1 \mathrm{~mm}$ dari ukuran sebenarnya. Toleransi ini dikategorikan sebagai instalasi tangga bus yang aman. Tangga yang dipasang menghasilkan akurasi seperti yang diinginkan. Mengurangi pekerjaan kontrol kualitas dengan akurasi yang diharapkan. Bapat menghindari kegagalan yang terjadi ketika tangga dipasang.
\end{abstract}

Kata kunci: Inspeksi, ketelitian, step, ultrasonik, sensor

\section{Pendahuluan}

Transportasi merupakan sarana yang dibutuhkan banyak orang sejak jaman dahulu dalam melaksanakan kegiatannya yang diwujudkan dalam bentuk angkutan [1]. Ada 3 (tiga) jenis pengangkutan yaitu pengangkutan darat, pengangkutan laut, dan pengangkutan udara yang semuanya itu diatur didalam Undang-Undang [2]. Kendaraan yang bisa mengangkut banyak penumpang contohnya adalah kereta, pesawat, kapal laut, bus. Angkutan umum yang sering di gunakan adalah bus [3]

Bus adalah salah satu jenis kendaraan angkutan yang cukup popular digunakan dalam kehidupan sehari-hari, sehingga bus harus dirancang secara baik dan benar. Proses perakitan bus dilakukan tahap demi tahap mulai dari proses perancangan produk (product design); pelepasan suku cadang (stripe off); rangka utama (main frame), perakitan body (body assembling); metal finish; dempul (putty); pengecatan (painting); trimming dan finishing hingga pre delivery inspection - PDI [4]. Semua pemasangan komponen membutuhkan ketepatan dan ketelitian yang tidak boleh melebihi batas toleransinya. Setiap komponen yang telah terpasang akan diperiksa dengan cermat oleh bagian quality control, meskipun komponen tersebut bukanlah komponen yang tidak terlihat langsung dari luar bus, seperti trap tangga.

Trap tangga merupakan komponen penting pada bus karena sebagai pijakan masuk dan keluarnya penumpang. Kendala atau kesalahan yang sering terjadi saat pemasangan trap tangga bus yaitu trap tangga yang terlalu naik, turun, 
ataupun terpuntir, dalam arti terlalu keluar atau masuk ke dalam dimana semuanya itu melebihi batas toleransi ukuran pemasangan trap. Dengan kendala tersebut maka operator sebelum melakukan las biasanya membutuhkan operator lain untuk mengamati trap tangga sudah lurus atau belum. Jika tidak ada operator lain yang membantu maka operator akan melakukan pengamatannya sendiri dengan naik ke lantai bus terlebih dahulu sehingga pemasangan akan mempersulit operator. Selain itu, pengamatan yang dilakukan secara langsung belum tentu akurat sesuai ukuran yang telah dibuat. Sehingga perlu membuat alat bantu pemasangan trap tangga bus dengan memanfaatkan sensor ultrasonik yang dirangkai dengan pemrograman arduino nano yang dibuat berdasarkan ukuran trap tangga belakang bus LEGACY SR 2 HD DG dengan chasis Hino/RK 8 JS. Manfaat dari alat bantu ketelitian ini operator terbantu untuk memasang trap tangga sendiri dan memiliki nilai ketelitian dengan toleransi $1 \mathrm{~mm}$ sehingga aman untuk pemasangan trap tangga bus.

Rumusan masalah dalam kajian ini adalah bagaimana mencapai ketelitian dan ketepatan toleransi untuk pemasangan tangga bus sesuai dengan yang telah ditentukan ?.

Tujuan dan manfaat dari kajian ini adalah merancang dan menerapkan alat bantu pemasangan tangga bus dengan sensor ultrasonic. Manfaat kajian adalah meningkatkan ketelitian dalam pemasangan tangga bus.

\section{Material dan Metodologi}

\subsection{Material}

Bahan yang digunakan adalah plat baja yang dipotong dan dibentuk sesuai dengan kebutuhan yang diperlukan untuk pembuatan alat bantu.

\subsection{Metodologi}

Pengumpulan data dan teknik pengumpulan data ini adalah demi mendapatkan data yang valid, sehingga hasil dan kesimpulan penelitian pun tidak akan diragukan kebenarannya [5]. Untuk melakukan pemrograman pada sensor, hal pertama yang harus dilakukan adalah pengambilan data trap secara langsung menggunakan alat bantu ukur yang biasa disebut rollmeter. Hasil pengukuran yang diperoleh adalah 3 tingkatan trap dengan ukuran seperti yang ditunjukkan pada Tabel 1 dan Gambar 1.

Tabel 1. Jarak trap ke rangka dan lantai

\begin{tabular}{ccc} 
Trap & Jarak ke Rangka Pintu & Jarak ke Lantai \\
\hline Trap 1 & $73 \mathrm{~cm}$ & $25,7 \mathrm{~cm}$ \\
Trap 2 & $56 \mathrm{~cm}$ & $51,2 \mathrm{~cm}$ \\
Trap 3 & $39 \mathrm{~cm}$ & $76,5 \mathrm{~cm}$ \\
\hline
\end{tabular}

Untuk menentukan nilai $\mathrm{Tb}$ 1, Ta 1, Tb 2, dan Ta 2 seperti yang ditunjukkan pada Tabel 2. Dengan menggunakan rumus dibawah ini :

$\mathrm{Tb} 1(\mathrm{n})=($ Jarak $\mathrm{n}$ ke rangka pintu $-5,5 \mathrm{~cm}($ lebar project borad $))-0,1 \mathrm{~cm}$

Ta $1(\mathrm{n})=($ Jarak $\mathrm{n}$ ke rangka pintu $-5,5 \mathrm{~cm}$ (lebar project borad $))+0,1 \mathrm{~cm}$

$\mathrm{Tb} 2(\mathrm{n})=($ Jarak $\mathrm{n}$ ke rangka pintu $-5,5 \mathrm{~cm}$ (lebar project borad) $)-2,5 \mathrm{~cm}$

Ta $2(\mathrm{n})=($ Jarak $\mathrm{n}$ ke rangka pintu $-5,5 \mathrm{~cm}$ (lebar project borad $))+1,5 \mathrm{~cm}$

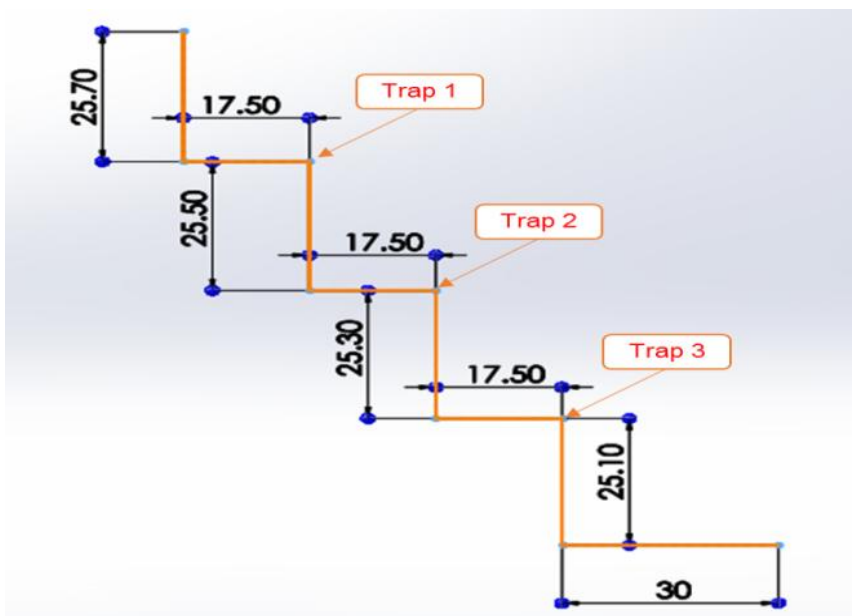

Gambar 1. Simulasi gambar teknik trap belakang bus LEGACY SR 2 HD DG dengan chasis Hino/RK 8 JS

\section{Keterangan:}

n : tingkatan trap

Ta 1 : titik batas atas Led hijau

Tb 2 : titik batas bawah Led merah
Tb 1 : titik batas bawah Led hijau

Ta 2 : titik batas atas Led merah 
Tabel 2. Nilai titik batas

\begin{tabular}{ccccc}
\hline Trap & Tb 1 & Ta 1 & Tb 2 & Ta 2 \\
\hline Trap 1 & 67,4 & 67,6 & 65 & 69 \\
Trap 2 & 50,4 & 50,6 & 48 & 52 \\
Trap 3 & 33,4 & 33,6 & 31 & 35 \\
\hline
\end{tabular}

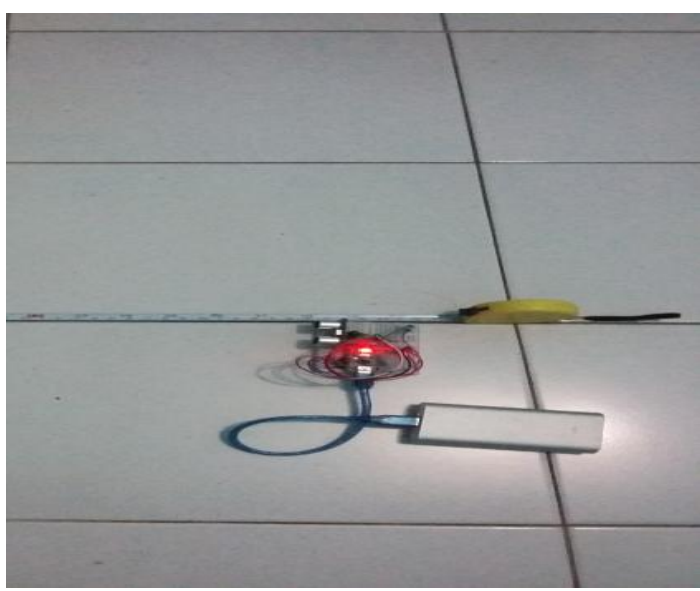

Gambar 2. Uji coba

Input data ke program. Memasukkan program ukuran tersebut yang harus dibaca sensor. Ukuran yang diinput memerlukan perhitungan terlebih dahulu sesuai dengan data yang diambil dalam lapangan serta mempertimbangkan lebar project board dan ketelitian sensor ultrasonik sebesar $3 \mathrm{~mm}$ atau $0,3 \mathrm{~cm}$.

Pengujian penulisan program. Pengujian penulisan program untuk melakukan code checking [6]. Dalam pengujian ini menggunakan verify fiture. Jika telah sesuai dengan kaidah pemrograman maka akan muncul tulisan Done compiling dan akan dilanjutkan dengan tahap save atau menyimpan program yang telah dibuat [7]. Namun, jika kode yang dibuat belum sesuai kaidah pemrograman akan muncul tulisan mengenai bagian yang salah dan kesalahan kode tersebut harus dibetulkan.

Simpan program. Save fiture berfungsi untuk menyimpan sketch atau program yang telah dibuat. Proses ini dilakukan setelah verify berhasil. Tahap ini terbagi menjadi 2 yaitu Save As dan Save. Save As digunakan untuk menyimpan sketch yang baru pertama kali dibuat. Sedangkan save digunakan untuk menyimpan sketch yang telah mempunyai nama file. Ketika save dilakukan dan berhasil maka akan muncul tulisan Done Saving [7].

Unggah program ke prototype. Fitur upload berfungsi untuk melakukan kompilasi program atau kode yang telah dibuat menjadi bahasa yang dapat dipahami oleh Arduino atau dengan kata lain mengunggah program yang akan dipakai menuju Arduino yang ada di prototype [7]. Prosedur yang dilakukan adalah menghubungkan kabel USB antara personal computer desktop atau laptop dengan port USB di Arduino [8]. Selanjutnya, memilih port yang telah di install yang terdapat dalam menu Tools. Jika Upload berhasil maka akan muncul tulisan done uploading.

Pengujian prototype. Beberapa hal yang dibutuhkan dalam tahap uji coba adalah aliran listrik yang berguna untuk mengaktifkan alat agar dapat berfungsi melalui kabel USB yang dihubungkan antara arduino dengan sumber aliran listrik. Aliran listrik dapat diperoleh melalui $P C$ maupun Power Bank [9]. Hal yang dibutuhkan selanjutnya adalah alat ukur panjang atau yang biasa disebut roll meter. Alat ukur ini dibutuhkan untuk mengukur jarak yang terbaca oleh sensor sesuai program yang telah dibuat. Benda padat juga merupakan hal yang dibutuhkan dalam melakukan uji coba, karena agar sensor dapat membaca jarak maka harus ada benda yang dijadikan sebagai obyek ukur. Benda ini dapat berupa buku, handphone, maupun tembok [10]. Dalam uji coba ini, penulis mengatur posisi sensor ultrasonik hingga nyala lampu terlihat sesuai dengan nilai yang dimasukkan kedalam program, serta menggunakan tembok sebagai obyek yang dibaca oleh sensor, karena tembok selalu statis atau tidak bergerak sehingga akan lebih akurat terhadap pembacaan [11]. Uji coba alat seperti ditunjukkan pada Gambar 2.

\section{Hasil dan pembahasan}

\subsection{Pengukuran}

Pengukuran adalah serangkaian kegiatan yang bertujuan untuk menentukan nilai suatu besaran dalam bentuk kwantitatif [12]. Pengukuran bertujuan untuk membandingkan nilai input sensor yang telah di program dengan hasil pengukuran sebenarnya [13]. Berikut ini adalah perbandingan pengukuran menggunakan program dan pengukuran menggunakan meteran seperti ditunjukkan pada Tabel 3 dan Tabel 4.

Hasil didapatkan bahwa jarak hasil pengukuran sebenarnya tidak sesuai dengan nilai input program dengan nilai geser yang berbeda-beda pada masing - masing trap. Ini dikarenakan pengaruh error yang ditimbulkan berdasarkan jauhnya jarak obyek yang diukur, tetapi untuk ketelitian dari hasil sebenarnya dengan program yang diinput sudah sesuai. Selain itu, didalam percobaan dapat dianalisis bahwa nyala lampu ketika sedang berada pada jarak yang sama dengan 
Tabel 3. Pengukuran titik batas 1

\begin{tabular}{ccccc}
\hline & Tb 1 Program & Ta 1 hasil pengukuran & Tb 2 program & Ta 2 hasil pengukuran \\
\hline Trap 1 & $67,4 \mathrm{~cm}$ & $67,6 \mathrm{~cm}$ & $65 \mathrm{~cm}$ & $69 \mathrm{~cm}$ \\
Trap 2 & $50,4 \mathrm{~cm}$ & $50,6 \mathrm{~cm}$ & $48 \mathrm{~cm}$ & $52 \mathrm{~cm}$ \\
Trap 3 & $33,4 \mathrm{~cm}$ & $33,6 \mathrm{~cm}$ & $31 \mathrm{~cm}$ & $35 \mathrm{~cm}$ \\
\hline
\end{tabular}

Tabel 4. Pengukuran titik batas 2

\begin{tabular}{ccccc} 
& Tb 1 Program & Ta 1 hasil pengukuran & Tb 2 program & Ta 2 hasil pengukuran \\
\hline Trap 1 & $65 \mathrm{~cm}$ & $65,5 \mathrm{~cm}$ & $69 \mathrm{~cm}$ & $69,5 \mathrm{~cm}$ \\
Trap 2 & $48 \mathrm{~cm}$ & $48,2 \mathrm{~cm}$ & $52 \mathrm{~cm}$ & $52,2 \mathrm{~cm}$ \\
Trap 3 & $31 \mathrm{~cm}$ & $31,1 \mathrm{~cm}$ & $35 \mathrm{~cm}$ & $35,1 \mathrm{~cm}$ \\
\hline
\end{tabular}

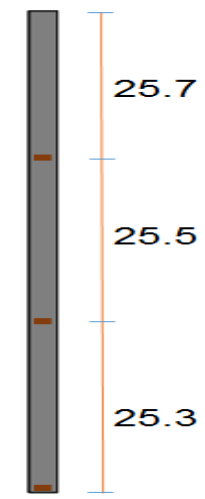

Gambar 3. Prototype alat bantu ketelitian pemasangan trap tangga

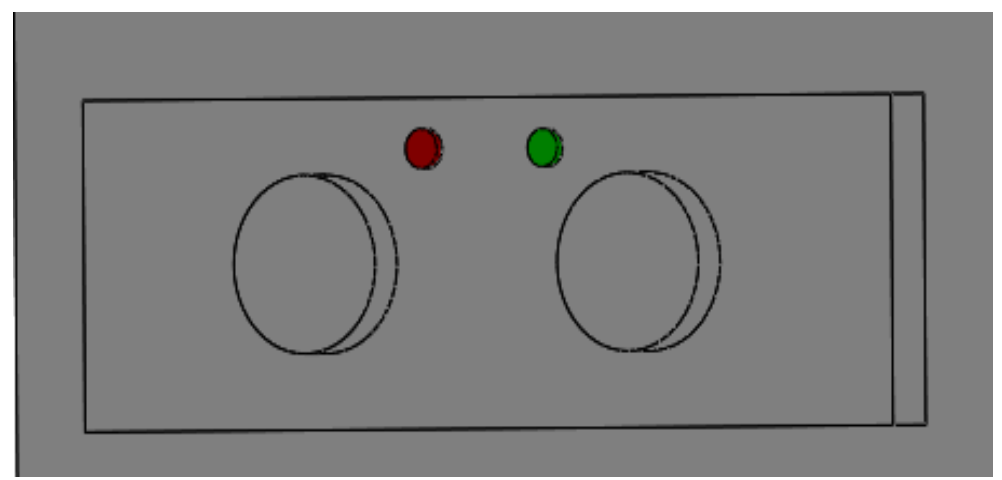

Gambar 4. Tampilan depan tempat meletakkan rangkaian sensor

jarak batasnya maka lampu terkadang akan mati, namun ketika sudah berada diantara batas itu maka lampu akan menyala terus. Oleh karena itu, agar sensor ini tetap dapat digunakan sebagai alat bantu pemasangan trap seperti ditunjukkan pada Gambar 3 dan Gambar 4.

Pada Gambar 3 diatas terdapat ukuran ketinggian menempatkan sensor ultrasonik. Untuk trap pertama, sensor ultrasonik diletakkan dengan acuan lantai pada jarak $25,7 \mathrm{~cm}$, untuk trap kedua pada jarak 51,2 cm, dan trap ketiga pada jarak 76,5 cm. Sedangkan Gambar 4 merupakan tampilan depan tempat meletakkan rangkaian sensor. Untuk 2 lingkaran yang besar merupakan tempat sensor ultrasonik serta lingkaran kecil berwarna hijau dan merah merupakan tempat Led [14].

\subsection{Prosedur pemasangan trap}

SOP pemasangan trap lantai, operator ditentukan sebanyak 2 orang [15]. Namun dalam kenyataannya operator berfokus pada masing-masing trap lantai seperti trap bagian depan dan trap bagian belakang, sehingga dalam operator lebih sering memasang trap sendiri tanpa bantuan operator lain.

\section{Kesimpulan}

Dari hasil analisis program sensor ultrasonik berdasarkan data jarak trap tangga belakang bus LEGACY SR 2 HD $D G$ dengan chasis Hino/RK $8 J S$ dapat diperoleh beberapa kesimpulan. Ketelitian pemasangan trap dapat tercapai dengan toleransi $1 \mathrm{~mm}$, dengan cara ini operator terbantu untuk memasang trap tangga sendiri tanpa bantuan oprator lain dengan ketelitian sesuai dengan yang d inginkan. Cara ini bisa mengurangi pekerjaan inspeksi yang dilakukan oleh quality control pada pemasangan trap belakang, sehingga dengan demikian pekerjaan menjadi lebih 
cepat dengan ketelitian sesuai yang diharapkan. Cara ini bias menghindari kegagalan posisi horisonta maupun vertical yang terjadi ketika trap tangga sudah dipasang.

\section{Daftar pustaka}

[1] Biro Komunikasi dan Informasi Publik Badan Penelitian dan Pengembangan. (2017). Transportasi Sebagai Pendukung Sasaran Pembangunan Nasional. http://www.dephub.go.id/post/read/transportasi-sebagai-pendukungsasaran-pembangunan-nasional. Diunduh pada tanggal 13 Juli 2018 jam 11.00 wib.

[2] LKHS FH UNSOED. (2017). Hukum Pengangkutan Darat di Indonesia. http://lkhs.blogspot.com/2017/10/hukumpengangkutan-darat-di-indonesia.html. Diunduh pada tanggal 14 Juli 2018 jam 10.00 wib.

[3] Wikipedia. (2017). Transportasi Umum. https://id.wikipedia.org/wiki/Transportasi_umum. Diunduh pada tanggal 14 Juli 2018 jam 12.00 wib.

[4] Santcawarti, BF, dkk. (2016). Gangguan keseimbangan sebelum dan setelah pemberian air kelapa hijau (cocos nucifera 1) pada pekerja pengecatan yang terpapar timbal (pb) di industri karoseri semarang. Jurnal kesehatan masyarakat (e-Journal). Volume 4. https://media.neliti.com/media/publications/105932-ID-none.pdf. Juli 2016. Diunduh pada tanggal 15 Juli 2018 jam 13.00 wib.

[5] Ciputra Uceo. (2016). Metode Pengumpulan Data dalam Penelitian. http://ciputrauceo.net/blog/2016/2/18/metodepengumpulan-data-dalam-penelitian. Diunduh pada tanggak 16 Juli 2018 jam 16.00 wib.

[6] Muhinjjaya. (2016). Software Testing. http://muhinjjaya.blogspot.com/2012/06/software-testing.html. Diunduh pada tanggal 16 Juli 2018 jam 17.00 wib.

[7] Riana. (2016). Testing dan Implementasi Sistem Informasi. http://fkomers.blogspot.com/2016/11/testing-danimplementasi-sistem.html. Diunduh pada tanggal 17 Juli 2018 jam 20.00 wib.

[8] Jogja Robotika. (2015). Komunikasi Serial Arduino dengan Komputer PC. http://www.jogjarobotika.com/blog/ komunikasi-serial-arduino-dengan-komputer-b102.html. Diunduh pada tanggal 17 Juli 2018 jam 22.00 wib.

[9] Qoirudin, Dedy. (2017). Belajar Arduino \#3 - Arduino Software (IDE). https://dedyqoirudin.wordpress.com/ 2017/02/23/ belajar-arduino-3-arduino-software-ide/. Diunduh pada tanggal 18 Juli 2018 jam 14.00 wib.

[10] Oktariawan,dkk. (2013). Pembuatan Sistem Otomasi Dispenser Menggunakan Mikrokontroler Arduino Mega 2560. http://journal.eng.unila.ac.id/index.php/fema/article/view/46. Diunduh pada tanggal 18 Juli 2018 jam 15.00 wib.

[11] Santoso, H. (2015). Cara Kerja Sensor Ultrasonik, Rangkaian, \& Aplikasinya. https://www.elangsakti.com/ 2015/05/sensor-ultrasonik.html. Diunduh pada tanggal 18 Juli 2018 jam 21.00 wib.

[12] Sastra, Tafsiri. (2013). Pengukuran Teknik dan Instrumentasi. https://blog.ub.ac.id/sastratafsier/2013/ 02/22/ pengukuran-teknik-dan-instrumentasi/. Diunduh pada tanggal 18 Juli 2018 jam 23.00 wib.

[13] Rahayu, D. (2014). Pengukuran Angka Indeks. https://desirahayu27.wordpress.com/2014/11/13/pengukuranangka-indeks/. Diunduh pada tanggal 19 Juli 2018 jam 10.00 wib.

[14] Yusup, J. (2017). Sistem Kendali Jembatan Otomatis. http://yusupjunaedi-namikaze.blogspot.com/2017/03/sistemkendali-jembatan-otomatis.html. Diunduh pada tang-gal 19 Juli 2018 jam 13.00 wib.

[15] Santosa, JD. (2014). Lebih Memahami SOP (Standard Operation Procedure). http://onesearch.id/Record/ IOS6.INLIS000000000024751/Description\#description. Diunduh pada tanggal 19 Juli 2018 jam 14.00 wib. 